\title{
INDICADORES DA PRESENÇA DE CONTEÚDOS DE HISTÓRIA E FILOSOFIA DA CIÊNCIA EM LIVRO DE TEXTO DE GEOLOGIA INTRODUTÓRIA
}

\section{Indicators of occurrences for content of History and Philosophy of Science in textbook of Introductory Geology}

Pedro Wagner Gonçalves ${ }^{1}$

Resumo: A literatura de ensino de Ciências e de Geologia assinala a importância de integrar aspectos históricos e filosóficos ao processo educacional (HPS). Denominamos isso de abordagem metodológica para ensino de ciências (MAS).

De outro lado, vários trabalhos sugerem que os livros didáticos são importantes para selecionar e organizar os programas de disciplinas. Livros exercem influência na formação de pesquisadores e profissionais. Isso conduz a investigar conteúdos metodológicos presentes em livros didáticos de Geologia Introdutória. O estudo demonstra a presença do pensamento de James Hutton (1726-1797) e Charles Lyell (1797-1875), bem como de outros aspectos históricos, que sugerem importância pedagógica da MAS no material didático examinado.

Unitermos: ensino de Geociências, História e Filosofia da Ciência, livro didático, História da Geologia, James Hutton (1726-1797), Charles Lyell (1797-1875)

Abstract: Articles on the teaching of science and Geology defend the importance of integrating historical and philosophical aspects in educational processes (History and Philosophy of Science approach or HPS), we call it the methodological approach of science (MAS). On the other hand, several works suggest that textbooks are important into selecting and organizinge programs of scientific disciplines overall in Brazil. These books seriously generate important influence on the formation of geologists, geographers, biologists, etc. These elements lead to research in the methodological contents in didactic books of Introductory Geology. The study demonstrates the presence of James Hutton's and Charles Lyell's thought in an textbook used in Brazilian undergraduate courses, as well as other historical aspects which suggests certain pedagogical importance of $M A S$ inon the examined didactic material.

Keywords: teaching of Earth Sciences, History and Philosophy of Science, text book, History of Geology, James Hutton (1726-1797), Charles Lyell (1797-1875)

\section{Introdução}

Amaral (1981) faz levantamento exploratório sobre características de livros de Geologia Introdutória. ${ }^{2}$ Constrói técnica descritiva capaz de indicar os tópicos abordados em cada uma das 40 obras examinadas. Seu instrumento está organizado sobre características epistemológicas da ciência: objeto da Geologia, método da investigação geológica e aplicação da Geologia. Cada uma dessas grandes dimensóes é subdividada em categorias menores que se aproximam de temas comuns tratados pelo ensino.

A dimensão Objeto da Geologia é dividida em aspecto físico e aspecto histórico. Subdivisões conduzem a termos encontrados nos capítulos de cada livro de texto examinado, p.ex.: crosta externa continental ou espaço extraterrestre sistema solar. Neste nível de análise itens tais como ciclo das rochas ou origem do sistema solar podem ser incluídos no quadro descritivo.

\footnotetext{
${ }^{1}$ Departamento de Geociências Aplicadas ao Ensino. Instituto de Geociências. Universidade Estadual de Campinas. E-mail: pedrog@ige.unicamp.br

${ }^{2}$ Adota-se a tradicional delimitação de Geologia Introdutória: ensino global e integrado do conteúdo geológico em nivel superior (Cunha 1995). Isso inclui o ensino que usualmente recebe as denominaçôes de Geologia, Geociências, Ciências da Terra, Ciência do Sistema Terra etc.
} 
Analogamente, a dimensão Método da investigação geológica recebe divisões sucessivas (físico ou histórico) até alcançar grandes campos identificáveis dentro de cada obra, p.ex.: método geofísico dentro de métodos físicos para incluir estudos sobre estrutura interna da Terra baseados na velocidade de ondas sísmicas (tópico comum dentro dos livros de Geologia).

O mesmo esquema ajudou a identificar a Aplicaşão da Geologia e possibilitou constatar a existência de assuntos relativos à Geologia ambiental, Mineração etc.

Embora o instrumento seja exaustivo e passível de ser aplicado a qualquer livro de Geologia Introdutória, parcela dos conteúdos tratados não pode ser percebida pelo instrumento. Amaral (1981), então, acrescenta mais duas dimensōes (sem qualquer tipo de subdivisão): História da Geologia e Outras dimensões. Nota, ainda, que a dimensão História da Geologia está presente em significativa parcela dos livros examinados.

A técnica empregada não identifica que conteúdos da História da Geologia foram abordados. Aspectos da História da Ciências foram incluídos em outras dimensōes. Não é clara a existência de nexos entre História das Ciências e Métodos de investigação. Em nossa pesquisa reelaboramos a técnica de Amaral (1981) e privilegiamos índices que permitem identificar a História das Ciências e da Geologia. Revelamos vínculos destas com raciocínios metodológicos. Tal conjunto de aspectos ajuda a caracterizar a natureza da ciência veiculada por livros de texto e pode ser usado para qualquer livro. Nos limites deste trabalho, aplicamos a técnica de descrição à obra Decifrando a Terra (Teixeira et al. 2000).

É notória a importância de livros didáticos de ciências na formação dos profissionais. Desde o trabalho clássico de Kuhn (1978) o assunto foi exaustivamente tratado. Sob enfoque psicológico, antropológico ou sociológico considera-se que os livros didáticos desempenham papel nuclear na formação de linguagens e crenças adotadas de cada ciência. O livro de texto poderia, ainda, servir para repetição de argumentos e valores. No Brasil isso é crucial: por longo período de tempo houve ausência de inovação em livros de Geologia Introdutória. Cunha (1995) constata que no ensino de Geologia o livro de texto é a principal referência para selecionar e organizar programas e conteúdos ministrados, conclui, ainda, que a obra de Leinz \& Amaral (1980), Geologia Geral, dominava o mercado editorial daquela época. O texto teve diversas ediçóes desde 1961 e, depois, em passado mais recente, foi sucessivamente reimpresso (sem revisão de conteúdo ou abordagem). Somente em 2000 foi publicado um novo livro que amplia a abrangência dos assuntos tratados, apresenta teorias e explicaçōes atualizadas e tem especial cuidado com as ilustraçôes. Este livro é o alvo do exame aqui exposto. No final de 2004, já haviam sido vendidos 22000 exemplares do Decifrando a Terra (informação oral de Wilson Teixeira).

\section{Objetivos}

O objetivo central desta investigação é diagnosticar a abordagem metodológica para o ensino de ciências por meio da presença de aspectos históricos e metodológicos em livro de texto de Geologia Introdutória. Para tanto, foi privilegiado o pensamento de James Hutton (1726-1797) e Charles Lyell (1797-1875) e mençōes à História da Geologia e das Ciências.

A investigação debruçou-se sobre moderno livro de Geologia Introdutória publicado no Brasil. Procurou-se identificar menções e citaçôes que remetem aos naturalistas James Hutton e Charles Lyell e/ou, ao seu pensamento, bem como identificar suas teorias, explicações ou elementos metodológicos centrais formulados por eles nos século XVIII e XIX. Isso se dá no âmbito da descrição de elementos históricos presentes em materiais didáticos e das funçôes semânticas, pedagógicas e epistemológicas que desempenham no ensino de Geociências. 
Indicadores da presença de conteúdos...

Dessa maneira, foi construída uma técnica que permite examinar conteúdos históricos e epistemológicos em livros voltados para o ensino das Ciências da Terra.

\section{Relevância dos livros didáticos e importância da presença de História e Filosofia da Ciência (HPS)}

Investigações que tratam de livros didáticos para ensino de Ciências indicam significativa diversidade. Encontram-se aspectos específicos de comunicação (p.ex.: Stylianidou et al. 2002, Cobo Merino \& Batanero 2004, Campanario 2003, González Rodríguez et al. 2003), de metodologia de ensino (p.ex.: Pandiella et al. 2003, García Barros \& Martínez Losada 2003) etc. Fracalanza (1993) e Megid Neto (1998) revelam distintos assuntos e abordagens nas pesquisas sobre livros didáticos. Tal literatura sugere a relevância de tais estudos. Livros didáticos exibem múltiplas dimensões e acham-se vinculados ao ensino de ciências conforme é exposto por Megid Neto \& Fracalanza (2003). Vários trabalhos esmiúçam o tratamento de História das Ciências em obras didáticas (p.ex.: Assis \& Zylberstajn 2001, Muñoz Bello \& Bertomeu Sánchez 2003). É dentro destes estudos que situa-se a presente análise.

Estudos feitos no Brasil sobre livros didáticos de Geologia remontam à análise de Amaral (1981) e Cunha (1986). O primeiro faz um levantamento exploratório de 40 livros de texto geológicos e revela as tendências principais de conteúdo e enfoque. Como já foi mencionado, adota como dimensões principais de análise o objeto da Geologia, o método da investigação geológica e a aplicação da Geologia. Para cada uma das dimensões procura situar a existência ou inexistência de referência explícita na unidade adotada para análise, o capítulo do livro. A pesquisa revela que a História da Geologia e das Ciências é tópico comum nos livros de Geologia Introdutória mas não especifica que conteúdos históricos ou filosóficos foram incorporados aos textos.

Aqui ampliamos a relevância dos aspectos históricos para a dimensão central de análise. Reunimos a História das Ciências a algumas implicaçôes epistemológicas para identificar raciocínios metodológicos que revelam elementos importantes adotados pelos autores de livros didáticos. Dessa forma, avançamos a descrição de pontos metodológicos centrais que foram apenas mencionados no trabalho de Amaral (1981).

Cunha (1986) identifica a coerência dos livros brasileiros mais comuns da época ao tratar a teoria geossinclinal. Compara as pretensões explícitas em Prefácio e Introdução com o desenvolvimento de tema nuclear do entendimento dos processos geológicos (teoria geossinclinal).

Acha-se implícito nas pesquisas mencionadas a relevância aos materiais didáticos para orientar as atividades pedagógicas. Dessa maneira, identificar, descrever e examinar conteúdos e enfoques presentes nos livros didáticos é contribuir para compreender o que é ensinado aos estudantes.

Matthews (1994: 47) assinala a importância das dimensões culturais da ciência, sua história, seus aspectos filosóficos e suas implicaçōes morais e religiosas para o ensino de ciências tornar-se mais reflexivo e significativo.

O estudo histórico da pesquisa do pêndulo, feita nos séculos XVI e XVII, marcado pelas contribuições de Isaac Newton e Galileu Galilei, seus nexos com o aperfeiçoamento do relógio mecânico e a determinação mais precisa da longitude, revelam a possibilidade de integração de conceitos de diferentes ramos do conhecimento humano (Matthews 1998).

Tal abordagem é uma das opções destinadas a introduzir História e Filosofia no ensino de Ciências. $\mathrm{O}$ enfoque metodológico pode favorecer a associação de idéias formando conceitos integrados e mais sólidos - dificuldade insistentemente perseguida no ensino de Ciências, como pode se depreender das sugestôes de Thompson (2001) para o ensino de Geociências. 
Matthews (1994: 49-50) lista possíveis argumentos favoráveis ao uso de História da Ciência no ensino. Dentre eles enfatizamos: promove a melhor compreensão dos conceitos e métodos científicos, é necessária para compreender a natureza da ciência, contrapóe o cientificismo e o dogmatismo que freqüentemente caracterizam aulas e textos de ciências, admite nexos entre tópicos de uma disciplina, bem como relaçōes de disciplinas diferentes.

Isso nos conduz a investigar a presença, a ausência e a forma como certo elemento histórico é utilizado em material didático destinado ao ensino de ciências. Defendemos o seguinte ponto de vista: por meio da referência a aspectos de Filosofia e História da Ciência pode-se aproximar e integrar conceitos fornecendo uma visão mais próxima da construção da ciência e a isso denominamos abordagem metodológica (MAS) do ensino, pois incorpora aspectos filosóficos e históricos revelando a natureza da ciência. Isso torna os conceitos mais claros e compreensíveis para os alunos.

\section{Técnicas para investigar MAS em livros de Geologia Introdutória}

Assis \& Zylbersztajn (2001) sugerem um modo de fazer uma investigação e descobrir a influência de um autor clássico em livros de texto de Física utilizados no nível Superior. Demonstram que tal influência pode estar presente sem qualquer menção explícita ao pensador ou a suas teorias.

Isso sugere que muitas vezes os autores de livros didáticos optam por não fazer referência a suas fontes e, ao mesmo tempo, podem ser identificadas pelas teorias defendidas, linguagem utilizada ou, mesmo, mediante a refutação de certos pontos de vista.

Tais observaçôes conduziram às formas que foram adotadas para caracterizar a influência de pensadores considerados clássicos para instauração da moderna Geologia (Hutton e Lyell).

Rodríguez \& Niaz (2002) estudaram como livros didáticos de Química veiculam a história dos modelos atômicos. Buscaram conceitos e experimentos cuja importância histórica ajudaria a compreender a evolução dos modelos atômicos. Os contextos científicos de experimentos e ambientes de conflito ajudariam a entender a história desses modelos, bem como a história da própria química. Nos livros analisados há desde a simples menção até construções mais completas das noçōes históricas envolvidas.

Nosso trabalho procurou identificar a influência dos naturalistas James Hutton e Charles Lyell no material didático. Fizemos um levantamento de ocorrências explícitas e implícitas de conceitos e fórmulas oriundos dos dois pensadores. Buscamos verificar quais as funçôes metodológicas da citação no contexto do argumento empregado pelos autores do livro didático. Procuramos, ainda, o pensamento dos clássicos por meio do uso de idéias e conceitos sem referência explícita a Hutton ou Lyell.

James Hutton: the founder of modern geology. Este título serviu a diversos autores de diferentes épocas, desde o século XIX. Foi além disso, o epíteto indiscriminadamente aplicado ao pensador britânico do século XVIII, atribuindo-lhe o papel heróico de Pai da Geologia. O título, por um lado, revela algo sobre sua carreira e trajetória pessoal, por outro, encobre toda uma gama de preocupaçôes dele mesmo, de sua época e de sua influência no ensino.

Os livros de Geologia Introdutória freqüentemente mencionam aspectos da vida e da obra de Hutton. Lyell freqüentemente é lembrado nos livros de texto pela controvérsia relativa ao uniformitarismo.

Os dois naturalistas escoceses estão entre os personagens mais mencionados em livros de Geologia Introdutória e tais referências puderam ser mapeadas no Decifrando a Terra. De fato, a dificuldade aparece quando os autores preferem não fazer citação direta e apenas utilizam certos 
instrumentos metodológicos reportáveis aos autores clássicos. Isso conduz a perguntar: que conceitos, noçóes, idéias, podem ser associados a Hutton e Lyell? Que limites e ambigüidades são incorporados ao estudo?

Busca-se identificar certos conceitos-chave usualmente atribuídos a Hutton e Lyell. Os divulgadores de suas idéias criaram certa imagem que, ao longo do tempo, foi sedimentada a tal modo que certos artigos específicos reforçam as mesmas noções (p.ex.: Oldroyd, 2000). $\mathrm{O}$ que caracteriza tais registros?

Hutton e Lyell foram profundamente vinculados a aspectos metodológicos dos estudos da Terra. Noções tais como tempo geológico e princípios usados para ordenar a escala de tempo relativo, atualismo, catastrofismo, foram reforçadas como elementos que tomaram parte de controvérsias e debates em que eles se envolveram e que marcaram a História da Geologia daquela época. Como essa é a visão conhecida dos autores, adotamos certos conceitos e argumentos que remetem a:

- raciocínio analógico e comparativo para interpretar fenômenos do passado;

- argumentos que exploram raciocínios temporais;

- figuras, fotografias ou outros diagramas visuais usados para formar nexos diacrônicos.

Buscou-se princípios que estruturam noçōes estratigráficas (temporais), elementos que caracterizam o pensamento atualista e controvérsias sobre origem de rochas. Tais tópicos caracterizam um modelo que representa aspectos relevantes e de interesse nos estudos geológicos modernos.

É importante assinalar que, de nosso ponto de vista, poderiam existir outras contribuiçôes conceituais a partir do pensamento de Hutton e Lyell para o ensino de Geociências, mas esses são elementos mais insistentemente mencionados. Os tópicos relativos à classificação de rochas, abordagens de fenômenos cíclicos no tempo geológico, certas interpretaçôes sobre fósseis etc., poderiam receber um aporte das sugestôes e contribuições desses autores.

\section{Livros didáticos no ensino de ciências}

Como procuramos demonstrar, os livros ajudam a formar a idéia de ciência dos alunos, sobretudo no Ensino Superior. Ao possibilitar o entendimento de teorias, explicações e fórmulas dominantes os livros desempenham a função de inculcar certos procedimentos e terminologias nos alunos que passam a aceitá-los como naturais.

Em nosso país houve quase que a completa ausência de renovação de livros destinados à Geologia Introdutória. Os livros mais modernos usados no Brasil eram oriundos de outros países, publicados em sua língua de origem e raramente traduzidos para o português. Além disso, exemplos e processos enfatizados muitas vezes acham-se distantes dos fenômenos geológicos de clima tropical e úmido. Isso facilitou um quase monopólio editorial do livro de texto de Leinz \& Amaral (1980) - como sugere Cunha (1995). Nesse panorama foi extremamente bem-vinda a edição do Decifrando a Terra.

\section{Descrição da organização da obra}

O livro é subdivido em 24 capítulos, precedidos de pequeno Prefácio (duas páginas). Depois do último capítulo, segue bibliografia complementar, apêndices e índice remissivo. Possui ao todo 568 páginas. 
O texto pode ser caracterizado como uma coletânea de artigos. Organizado por quatro autores, seus capítulos são assinados por mais de trinta especialistas. Quase todos do Instituto de Geociências da Universidade de São Paulo.

Os capítulos são divididos em itens (aqui denominados subtítulo de primeira ordem) os quais, por sua vez, são divididos em subitens (denominados subtítulo de segunda ordem) e alguns deles apresentam, ainda, partições menores.

A maioria dos capítulos possui de quatro a cinco subitens. $\mathrm{O}$ capítulo dois apresenta o menor número de divisões (dois subitens) e o capítulo quatro acha-se mais dividido (possui 14 subtítulos).

\section{Descrição do conteúdo da obra}

Os autores explicitam no Prefácio que a obra pretende tratar como a Terra funciona utilizando um escopo multidisciplinar. Pretendem, ainda, expor tal conteúdo mediante linguagem fácil.

Além disso, os autores são claros ao assinalarem que vão tratar de processos geológicos internos e externos e enfatizar exemplos brasileiros e sul-americanos.

A seqüência de temas inicia com um tópico característico dos primeiros livros de Geociências lançados no mercado na década de 1960: universo, evolução astrofísica, origem do sistema solar e do sistema Terra-Lua.

O segundo capítulo dedica-se aos materiais terrestres: minerais, rochas e ciclo das rochas.

De certo modo, implicitamente adota-se a idéia de que o estudo do planeta depende da evolução astrofísica de diferentes sistemas (sistema solar, sistema Terra-Lua e desenvolvimento da matéria no universo) e do conhecimento dos materiais da crosta terrestre (rochas e minerais).

Do terceiro ao quinto capítulo explora-se a estrutura interna da Terra por meio de métodos geofísicos. Esse bloco prepara o sexto capítulo. Neste a teoria da tectônica de placas é exposta. Este capítulo parece fechar uma unidade iniciada nos tópicos relativos à estrutura interna da Terra. Ao compor a idéia de que a Terra é um corpo cósmico e que o mecanismo fundamental que caracteriza e diferencia este planeta dos demais é a tectônica de placas completa-se um conceito integrado de planeta. Na seqüência, os capítulos seguintes devem proceder ao caminho analítico que foi anunciado no Prefácio: estudar os processos da dinâmica externa e interna.

Do sétimo ao décimo quarto capítulos trata-se da dinâmica externa da Terra.

O décimo quinto capítulo formula o conceito de tempo geológico relativo e absoluto. Trata-se de um capítulo eminentemente metodológico. Há forte ênfase a aspectos históricos, como pode ser notado no Quadro I (final do texto).

Os capítulos décimo sexto ao décimo nono tratam da dinâmica interna do planeta.

Os recursos naturais (hídricos, minerais e energéticos) são abordados do vigésimo ao vigésimo segundo capítulo. A exposição de tais tópicos como capítulos isolados sugere que esses são considerados as áreas de aplicação do conhecimento geológico.

Os dois últimos capítulos exploram tendências de desenvolvimento da natureza e da sociedade procurando caracterizar uma perspectiva ambiental.

O número de menções e observações sobre como os fenômenos geológicos podem se constituir em risco para a sociedade, bem como a utilidade atual ou potencial dos mesmos, ou de seus produtos, para utilização humana, sugere uma nítida tentativa de revelar a importância do conteúdo geológico por meio de aspectos ambientais. Dessa maneira, o livro pode ser considerado um texto de Geologia Introdutória com enfoque ambiental. Este enfoque é coerente com a preocupação explicitada pelos autores no Prefácio. 


\title{
A presença de conteúdos históricos e metodológicos no texto
}

Metade dos capítulos faz alguma referência à MAS: problema e/ou raciocínio que poderia ser remetido ao pensamento dos clássicos das ciências geológicas. Tratam-se de capítulos em que há menções esparsas e muitas vezes implícitas que remetem a como a ciência trabalha ou operou no passado. Como não há referências claras sobre a necessidade ou importância do conhecimento histórico, tais ocorrências aparentam ser apenas espontâneas. Esse tipo de tratamento é comum no livro e sugere que foi feito de modo casual.

Tal tratamento casual de exemplos históricos é bastante comum nos livros de texto científicos. Breves notas históricas também foram encontradas por Rodríguez e Niaz (2002) em seu estudo de livros de Química, o que, segundo eles, dificulta a incorporação dos temas históricos ao ensino de ciências.

Matthews (1994) enfatiza que é necessário refletir sobre que História e que casos históricos devem ser incluídos no ensino. A História deveria contribuir para tratar conceitos nucleares do ramo de conhecimento e facilitar o entendimento de idéias da ciência e dos cientistas.

No Decifrando... as citações esparsas a aspectos metodológicos acham-se concentradas nos capítulos dedicados à dinâmica externa (ver resumo no Quadro I). Em alguns capítulos há apenas uma citação isolada, em outros há duas ou três referências desse tipo que por seu conteúdo e, ou, por sua abordagem remetem a fórmulas de Hutton e Lyell. O trecho seguinte exemplifica esses casos (décimo capítulo Rios e Processos Aluviais):

\begin{abstract}
Os depósitos aluviais constituem um dos mais importantes componentes do registro geológico. Seu estudo, baseado em modelos estabelecidos a partir da observação de depósitos recentes, permite a caracterização dos processos hidrodinâmicos e a compreensão da evolução sedimentar dos depósitos antigos, fundamentais na distribuição dos recursos e na reconstituição da evolução tecto-sedimentar de uma bacia (p.192).
\end{abstract}

O raciocínio empregado é uniformitarista, incorpora a idéia de comparação e abre a possibilidade de transferência de informação no tempo. Trata-se de transferência de informação no tempo mas os autores não fazem referência direta a uniformitarismo, método analógico comparativo, a Hutton ou a Lyell. A referência temporal e histórica é explícita na menção à "reconstituição da evolução tecto-sedimentar", ou seja, foi adotado o método uniformitarista mas não houve um esforço de claramente demarcá-lo. Nas páginas 194-195 (Quadro 10.1 da obra) há mapas e fotos de lagos, a Fig. 10.7 representa materiais sedimentares (Formação Tremembé, Bacia de Taubaté) de paleolago de idade terciária que, comparado às demais figuras, representa implicitamente a idéia uniformitarista.

Assis \& Zylbersztajn (2001) notam que a influência de Ernst Mach é muito clara na definição de massa inercial e na discussão da estrutura não acelerada das estrelas fixas nos livros de Física analisados apesar da ausência de referências explícitas. Podemos dizer o mesmo de certas passagens dos capítulos dedicados à geodinâmica externa do Decifrando... Tal fato, pode estar associado à relevância de certos esquemas de raciocínio para construir os conceitos geológicos, embora os autores não considerassem crucial explicitar a metodologia empregada.

Em quatro capítulos (como pode ser observado no Quadro I) a presença de elementos históricos não deve ser casual, pois mereceu chamada em subtítulo repetidamente. Isso obrigou o texto a tecer consideraçōes claras e explícitas a problemas históricos.

Os capítulos que recorrem claramente à história tratam: estrutura interna da Terra, tectônica de placas, tempo geológico e rochas metamórficas. Em dois deles há menção explícita a Hutton e Lyell (tempo geológico e rochas metamórficas). 
Um dos capítulos do livro que trata da estrutura interna da Terra explora informações e métodos gravimétricos como fonte de dados sobre o planeta (capítulo quatro intitulado Investigando o Interior da Terra). A menção à História da Ciência diz respeito ao processo histórico que conduziu ao estabelecimento da Lei da Gravidade nos séculos XVI e XVII. Há referência explícita a Galileu Galilei e Isaac Newton.

No mesmo capítulo, os itens que explicam a isostasia e a relacionam aos processos de tectônica global, referem-se à descoberta desse fenômeno (com referências a J. H. Pratt e G. Airy). O tratamento da magnetosfera também mereceu uma citação histórica que recorreu à Antigüidade.

Esse quarto capítulo faz uma descrição das características dos campos magnético e gravitacional terrestres e procura revelar a importância das propriedades tratadas para os estudos geológicos acadêmicos e aplicados. A explicação sobre o dipolo magnético terrestre é especialmente clara e expõe os vínculos do modelo teórico e as evidências que lhe dão suporte científico. Mas, além disso, houve um esforço de referência histórica que não seria obrigatório se as autoras considerassem tal conhecimento supérfluo.

Dos quatro capítulos que fizeram menção explícita à História da Ciência, chama nossa atenção que usualmente os estudos petrológicos, em livros de texto de Geologia, não exploram tal assunto. Nos demais assuntos, embora não seja obrigatório, o uso da história no ensino não é inusitado. O capítulo sobre rochas metamórficas recorre a Hutton e Lyell (mencionados explicitamente), isso reforça a noção de que alguns autores consideram aspectos da evolução histórica do conhecimento como parte relevante do entendimento dos conceitos. Neste momento chama atenção que os capítulos que estudam vulcanismo e rochas magmáticas não mencionam Hutton, apesar da controvérsia entre plutonistas e netunistas.

O capítulo que expõe a teoria da tectônica de placas (sexto capítulo) usualmente recebe tratamento histórico nos livros didáticos. Remete-se a idéias iniciais sobre deriva continental, enfatiza o trabalho de Alfred Wegener e os dados sobre fundo oceânico (topografia, dados geomagnéticos, simetria de idades em torno das dorsais) são expostos simultaneamente como história e evidências para compreender a expansão do fundo oceânico. $\mathrm{O}$ capítulo investigado seguiu aproximadamente essa trajetória.

Do ponto de vista do livro, é necessário assinalar que os elementos geofísicos foram apresentados em capítulos anteriores e isso facilitou a exposição do sexto capítulo. Tal construção e organização de conteúdo revela-se facilitadora para o entendimento de tectônica de placas. No âmbito do livro, mencionamos que o capítulo décimo terceiro completa informaçôes que aclaram a teoria de placas (refere-se ao tópico: processos oceânicos e topografia oceânica especialmente da margem continental sul-americana).

O vigésimo terceiro capítulo busca caracterizar quais são as tendências da história da Terra (os ciclos naturais) e o que foi singular nessa história. Sua montagem depende do entendimento de vastas parcelas de conteúdo do livro e há várias passagens explorando idéias e raciocínios comparativos típicos da estrutura geológica de pensamento. Além disso, como apresenta-se no Quadro I, há uma menção explícita a Lyell para defender o catastrofismo. Esta passagem vincula $\mathrm{o}$ atualismo à contribuição lyelliana.

O capítulo que apresenta o maior número de mençōes a aspectos históricos e referências a Hutton e Lyell é o décimo quinto (Em busca do passado do planeta: tempo geológico). Se de um lado isso sugere que o tema tempo geológico usualmente é exposto junto com a história da ciência, por outro, é importante assinalar que o valor atribuído a esses aspectos é especialmente alto no livro sob análise (resumo exposto pelo Quadro I).

Títulos de itens (p.ex.: Como surgiu a Geologia e uma nova concepção do tempo) e subitens (p.ex.: James Hutton e a consolidação da Geologia como ciência) revelam que o fio condutor 
para desenvolver o assunto tem na história da Geologia um suporte essencial. As ilustrações assinalam naturalistas clássicos e contribuições que foram relevantes na elaboração da noção de escala do tempo geológico. Debates que contribuíram para alargar a duração da história da Terra receberam especial atenção na elaboração do capítulo.

Além do capítulo sobre tempo geológico explorar significativamente a história, há uma exposição crítica e uma construção conceitual que se aproveita da seqüência histórica para selecionar e construir conceitos cruciais que ajudam a imaginar as escalas do tempo geológico relativo e absoluto. As dúvidas sobre a duração da idade da Terra nos séculos XVIII e XIX, bem como suas controvérsias, ajudam o aluno a perceber o significado filosófico que a escala do tempo geológico representou para a cultura humana.

Dos argumentos favoráveis a introduzir História da Ciência (mencionados a partir de Matthews, 1994: 49-50), o que melhor se adapta ao tratamento do décimo quinto capítulo é a idéia de que a história contribui para melhorar o entendimento dos conceitos científicos.

\section{Conclusões}

Há diversas formas de manifestação de aspectos históricos e metodológicos no interior do livro sob análise. Tais elementos ocupam diferentes funções conceituais e semânticas na construção dos argumentos. Nota-se que em muitas ocasiōes as citações não se referem explicitamente ao entendimento de que se trata de um raciocínio típico do pensamento geológico e, tampouco, fazem menção a tratar-se de aspecto relevante do desenvolvimento da História da Geologia. Isso ocorre sobretudo nos capítulos dedicados à dinâmica externa da Terra. Tal montagem de argumentos sugere que os autores não estavam especialmente preocupados em veicular informações históricas e epistemológicas, mas episodicamente incluíram elaborações que revelam como os argumentos geológicos são construídos. Isto assinala que certos raciocínios empregados por Hutton e Lyell são relevantes para expor conceitos, explicações e modelos geológicos.

Ao lado da dispersão e de menções isoladas sobre História da Geologia, Hutton e Lyell, alguns capítulos claramente enfatizam a perspectiva metodológica. $\mathrm{O}$ décimo quinto capítulo combina e integra os dados históricos, as controvérsias ocorridas e a exposição dos conceitos e princípios nucleares para compreender o tempo geológico em suas dimensões relativa e absoluta. O capítulo Em busca do passado do planeta: tempo geológico revela elaboração guiada pela história da geologia e deste modo sugere como o conhecimento foi transformado e elaborado ao longo da história da ciência.

$\mathrm{O}$ vigésimo terceiro capítulo, $A$ Terra: passado, presente e futuro, revela outra articulação de aspectos metodológicos e a elaboração dos ciclos, tendências e singularidades da história da natureza. Utilizando raciocínios comparativos e históricos, sem enfatizar mençôes explícitas ao pensamento atualista, obteve uma idéia integrada de como a Geologia opera com conceitos e autodelimita-se entre as ciências naturais.

Os capítulos quarto, sexto e décimo oitavo trazem a História da Geologia do modo que poderíamos chamar de tradicional nos livros de textos: expõem com destaque fatos e personagens históricos. As informaçôes históricas servem como aspectos introdutórios ou complementares - abordagem bastante comum nos livros didáticos de Geologia.

A obra apresenta heterogeneidade no que tange aos aspectos analisados. Há capítulos que não incluíram aspectos históricos ou menções a Hutton e Lyell. Alguns capítulos optaram por descrever e classificar fenômenos e, conseqüentemente, os argumentos, pouca importância atribuíram aos argumentos narrativos e ao pensamento temporal que caracteriza os fenômenos geológicos. 
A seleção de aspectos relevantes de MAS pode ser feita para qualquer outra ciência e as descrições de ocorrências de tais elementos, apoiando-se na organização de capítulos e subitens, são aplicáveis a livros de texto de campos muito distantes dos estudos da Terra.

Agradecimentos

Reconhecimento é devido aos autores anônimos de pareceres que ajudaram a tornar o texto mais claro e objetivo.

\section{Referências}

AMARAL, I. A. do. O conteúdo e o enfoque dos livros de geologia introdutória. São Paulo, 1981. 259 f. Dissertação (Mestrado em Geologia Geral e de Aplicação) - Instituto de Geociências, Universidade de São Paulo, São Paulo, 1981.

ASSIS, A. K. T.; ZYLBERSZTAJN, A. The influence of Ernst Mach in the teaching of mechanics. Science \& Education, Dordrechet, v. 10, n. 1, p. 137-144, jan./mar. 2001.

CAMPANARIO, J. M. De la necesidad, virtud: cómo aprovechar los errores y las imprecisiones de los libros de texto para enseñar física. Enseñanza de las Ciencias, Barcelona, v. 21, n. 1, p. 161-172, 2003.

COBO MERINO, B.; BATANERO, C. Significado de la media en los libros de texto de secundaria. Enseñanza de las Ciencias, Barcelona, v. 22, n. 1, p. 5-18, 2004.

CUNHA, C. A. L. S. A. Geologia nos livros didáticos no Brasil: um estudo da coerência interna dos textos através do conceito de geossinclinal. 1986. 296 f. Dissertação (Mestrado em Educação) Faculdade de Educação, Universidade Estadual de Campinas, Campinas, 1986.

CUNHA, C. A. L. S. Geologia Introdutória nas instituições de ensino superior no Brasil: análise dos cursos de ciências e geografia. Campinas, 1995. 300 f. Tese (Doutorado em Educação) Faculdade de Educação, Universidade Estadual de Campinas, Campinas, 1995.

FRACALANZA, H. O que sabemos sobre livros didáticos para o ensino de ciências no Brasil. 1993. 302 f. Tese (Doutorado em Educação) - Faculdade de Educação, Universidade Estadual de Campinas, Campinas, 1993.

GARCÍA BARROS, S.; MARTÍNEZ LOSADA, C. Análisis del trabajo práctico en textos escolares de primaria y secundaria. Enseñanza de las Ciencias, Barcelona, v. 21, n. extra, p. 5-16, 2003.

GONZÁLEZ RODRÍGUEZ, C. et al. A qué contenidos relacionados con la fotosíntesis dan más importancia los textos escolares de secundaria? Enseñanza de las Ciencias, Barcelona, v. 21, n. extra, p. 77-88, 2003.

KUHN, T. A estrutura das revoluções científicas. São Paulo: Perspectiva, 1978. 262 p.

MATTHEWS, M. R. How history and philosophy in the US Science Education Standards could have promoted multidisciplinary teaching. School Science and Mathematics, Menasha, v. 98, n. 6, p. 285-293, out. 1998. 
MATTHEWS, M. R. Science teaching: the role of history and philosophy of science. New York: Routledge, 1994, 287 p.

MEGID NETO, J. O ensino de ciências no Brasil: catálogo analítico de teses e dissertações 1972-1995. Campinas: Editora da Unicamp, 1998. 217 p.

MEGID NETO, J.; FRACALANZA, H. O livro didático de ciências: problemas e soluções. Ciência \& Educação, Bauru, v. 9, n. 2, p. 147-157, 2003.

MUÑOZ BELLO, R.; BERTOMEU SÁNCHEZ, J. R. La historia de la ciencia en los libros de texto: la(s) hipótesis de avogadro. Enseñanza de las Ciencias, Barcelona, v. 21, n. 1, p. 147-159, 2003.

OLDROYD, D. James Hutton's "theory of the earth" (1788). Episodes, Ottawa, v. 23, n. 3, p. 196-202, 2000.

PANDIELLA, S. et al. Estrategias de recuerdo y comprensión de un texto de física. Enseñanza de las Ciencias, Barcelona, v. 21, n. extra, p.119-129, 2003.

RODRÍGUEZ, M. A.; NIAZ, M. How in spite of the rhetoric, history of chemistry has been ignorated in presenting atomic structure in textbooks. Science \& Education, Dordrecht, v. 11, p. 423-441, set. 2002.

SHULMAN, L.S. Knowledge and teaching: foundations of the new reform. Harvard Educational Review, Cambridge, v. 57, n. 1, p. 1-22, fev. 1987.

STYLIANIDOU, F. et al. Analysis of science textbook pictures about energy and pupils' readings of them. International Journal Science Education, London, v. 24, n. 3, p. 257-283, 2002.

TEIXEIRA, W. et al. Decifrando a Terra. São Paulo: Oficina de Textos, 2000. 558 p.

THOMPSON, D. Por uma educação em ciências da terra e do meio ambiente destinada a alunos entre os 4 e os 16 anos de idade. In: MARQUES, L.; PRAIA, J. (Coord.). Geociências nos currículos dos ensinos básico e secundário. Aveiro: Universidade de Aveiro, 2001. p. 131-165. 


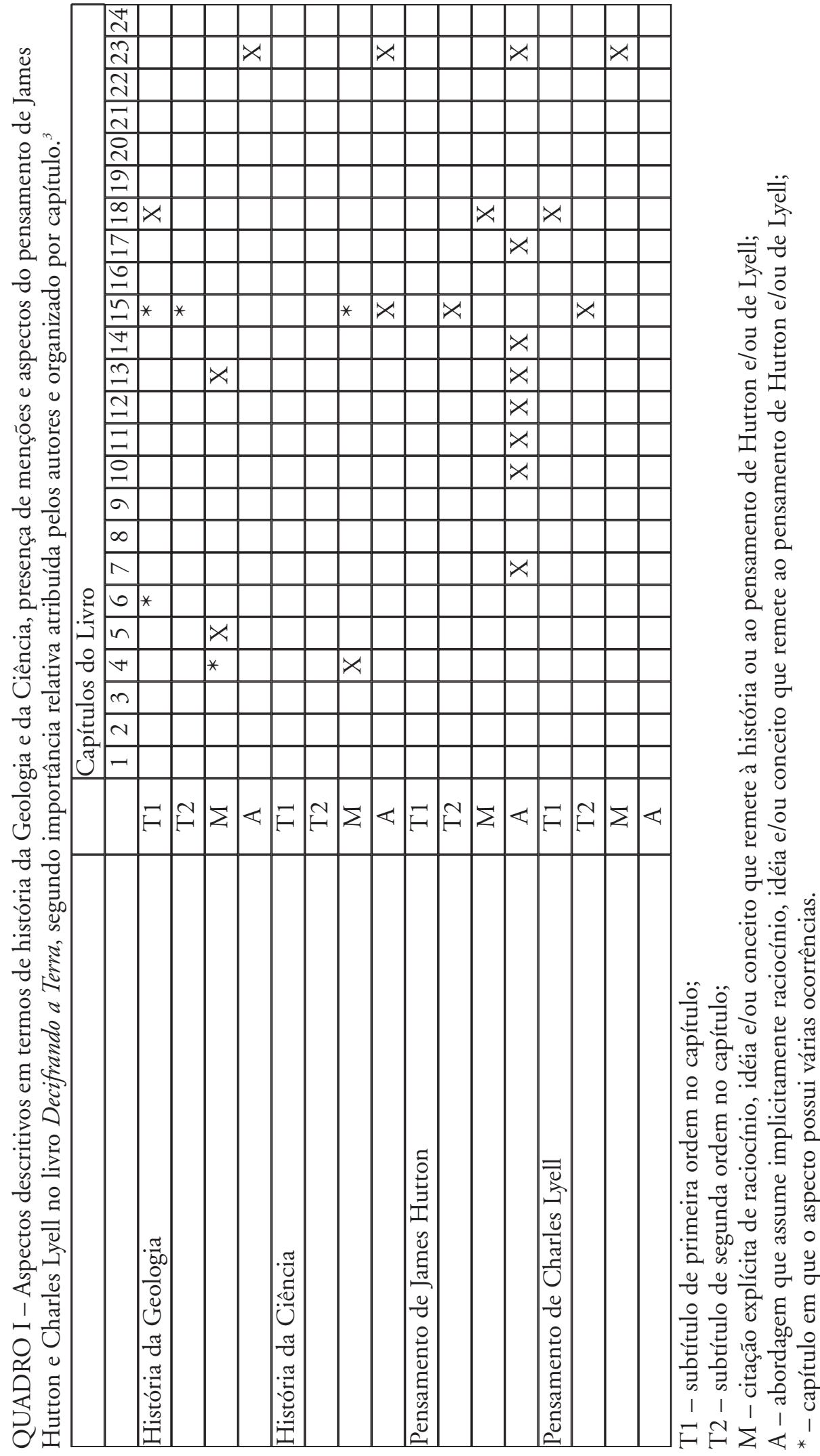

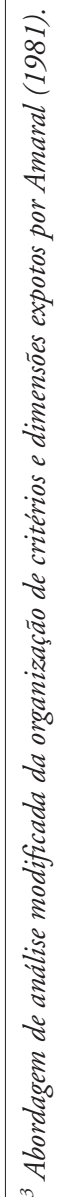

